\title{
Analysis on Aesthetic Education Implementation Paths in Colleges and Universities under Network Context
}

\author{
$\mathrm{Na} \mathrm{Qu}$ \\ Beijing International Studies University \\ Beijing, China 100024
}

\begin{abstract}
With the development and application of network technology, network has become a new education field besides family, school and society. Under the network context, facing the characteristics of cultural diversity, multidimensional nature of space and time as well as group interaction, the content of network aesthetic has also changed, including "knowing beauty", namely having good aesthetic standards and aesthetic knowledge, "understanding beauty", namely having good aesthetic ability and "creating beauty", namely creating excellent aesthetic works. Under such new situation, colleges and universities are required to strengthen the aesthetic education, to further strengthen the aesthetic theory education, promote aesthetic practice, set up a network aesthetic education team, thus to form the good cultural atmosphere for network aesthetic education.
\end{abstract}

Keywords—network; college aesthetic education

\section{INTRODUCTION}

Colleges and universities shoulder the responsibility of national talent cultivation, to cultivate the talents with allround development of morality, intelligence, physique and aesthetic as well as the integrated personality, so as to adapt to the requirements of modern society. As an important part of cultivating qualified talents, aesthetic education is valued by the state. It is proposed in the National Medium- and LongTerm Plan for Education Reform and Development that we shall strengthen aesthetic education, and cultivate students' good aesthetic sentiment and cultural accomplishment. In September 2015, the "Opinions on Comprehensively Strengthening and Improving School Aesthetic Education promulgated by the state council put forward the more specific requirements regarding aesthetic education. With the advent of new media era, network has become an indispensable part of college students and a new field of college aesthetic education besides family, school and society. How to strengthen college students' aesthetic education (hereinafter referred to as the "network aesthetic education") under network context, and improve college students' network aesthetic sentiment and humanistic accomplishment and improve college students' spiritual pursuit are the problems faced by us.

\section{CharaCteristics OF NETWORK AESTHETIC EDUCATION}

The traditional aesthetic education is generally concentrated in certain space situations, to improve people's beauty appreciation by stimulating people's feeling of beauty, so as to realize constant improvement of people's accomplishment. Network aesthetic education is a new type generated along with the rapid development of new media technology, especially the development of network, which is the aesthetic education within network context, having its own characteristics.

1) Diversity of culture: Due to the vast openness of network culture, the multi-culture with diverse forms and rich content are presented in front of teenagers in the forms of various images, video, etc., but the eroticism, violence, terror and other negative culture will also appear in their online life. The value outlook of youth is in a critical period of formation; therefore, the diverse network will have huge impact on the outlook with unstable aesthetic standard, which has deepened the difficulty of network aesthetic education to some extent.

2) Multidimensional nature of space and time: The appearance of network has broken time and space constraints of traditional aesthetic education process. Network's superspace feature has made network aesthetic education available anytime and anywhere, providing network aesthetic education with huge space and length of time, to enhance the convenience and possibilities of aesthetic education.

3) Group interaction: The traditional aesthetic education is mainly teacher-oriented, and that process is a process of enhancing aesthetic ability and perfecting personality through completing a certain study goal. In today's Internet age, the open network platform makes the teachers of network aesthetic education not just only confined to the real life, but will unconsciously participate in the interaction among huge number of netizens, and the netizens' aesthetic standards and aesthetic ability also influence the teenagers subtly in the process of online interaction.

\section{CONTENT OF NETWORK AESTHETIC EdUCATION}

There is no consensus between aesthetics circles and educational circles regarding connotation and related content 
of aesthetic education. There are following common views, namely, aesthetic education is the education to cultivate emotion; aesthetic education is art education; aesthetic education is education of aesthetic knowledge; aesthetic education is aesthetic conception education; aesthetic education is aesthetic ability education; aesthetic education is the education to shape people's good mind, etc. From the perspective of the purpose of aesthetic education, the ultimate goal of aesthetic education is to realize people's free and comprehensive development. [1]

The so-called network aesthetic education is to make young students feel the beauty within network context, to constantly improve their aesthetic sentiment and aesthetic idea with the beauty of network, thus to shape people's beautiful soul. In particular, the network aesthetic education focuses on cultivating young students to know, understand and create beauty.

\section{A. Knowing Beauty}

The so-called "knowing beauty" refers to facing the content and form within network space, and students can not only find beauty, but have a set of good aesthetic standards and aesthetic basic knowledge. French sculptor Rodin once said that beauty exists everywhere, as for our eyes, there no absence of beauty but the lack of discovery. The aesthetic education under network context guides people to feel and discover beauty in network, to be able to abandon false propaganda and harmful culture from the complicated network content and distinguish the truth, kindness and beauty, as well as pick out the harmonious and elegant beauty from the network visual impact of the bizarre color, structure and composition.

\section{B. Understanding Beauty}

The so-called "understanding beauty" is to be able to have higher aesthetic ability in network ecological space, to be able to perceive beauty, and have emotional resonance with beauty, so as to accept the edification of beauty. Network technology can express various beauties in a more stereo, intuitive and vivid manner. In the process of aesthetic education, the beauty shall not only be perceived form the surface level, but also shall from outward appearance to the inner essence, from form to content, so as to experience the deep-level beauty of network culture and experience the abundant emotion behind content, so as to achieve mental and psychological resonance and enjoyment, to really accept the edification of beauty.

\section{Creating Beauty}

The so-called "creating beauty" is to create excellent aesthetic works by means of various technical advantages of network and through imagination, including literature, fine arts, music, film and television, etc., so as to form a good flourishing situation with all people to create beauty. The openness and convenience of network has rendered more possibilities to create and present literary and artistic works, and has expanded the audience of aesthetic works, enabling more people to inspire creative inspiration in mutual exchanges, to produce more excellent aesthetic works, and make more young students feel the edification of beauty and touch their soul.

\section{PATHS OF NeTWORK AESTHETIC EDUCATION IMPLEMENTATION IN COLLEGES AND UNIVERSITIES}

\section{A. Strengthen the Education of Aesthetic Theoretical Knowledge}

Along with people's deepening understanding of aesthetic connotation, scholars' researches have shifted the understanding of aesthetic education from artistic beauty education to involving natural beauty and social beauty into the category of aesthetic education. Moreover, more and more scholars agree that aesthetic education is not only perceptual education, but also shall absorb the rational factors, and aesthetic education is the unity development of sensibility and rationality, and the "education formed after penetrating aesthetic principles in the teaching of various subjects", and a kind of "integrated education aiming to improve students' overall quality. [2] And it indicates that not only aesthetic theory education shall be strengthened, but also the aesthetic education shall run through the teaching of various subjects.

- Strengthen young students' knowledge of aesthetic theory. Network aesthetic education is not only to feel the beauty in the senses such as vision and hearing, the more important lies in rational level, which is the learning and understanding of aesthetic theory knowledge. The construction and research of aesthetic subject shall be strengthened in colleges and universities, and set up the course related to aesthetic theory, enable students to understand the basic knowledge of aesthetic and grasp the general rule and special rule of aesthetic appreciation, to be able to have strong artistic appreciation ability and aesthetic appreciation analysis ability. For example, when college students enter into various art museums online, they can recognize the art forms of carious beauties and know how to appreciate beauty from a certain perspective.

- Make the aesthetic education run through the teaching of various subjects. Beauty makes people produce the joyful feelings, and is able to inspire people's interest and curiosity. Make the aesthetic education run through various subject is not only beneficial to promote the teaching of these subjects, but also is conducive to make college students form good aesthetic habits. For example, teaching of some subjects with strong theoretical property, such as advanced mathematics and college physics, and paying more attention to the interpretation of theoretical knowledge. If students can experience the marvellous behind the numbers and principles, the beauty of human thinking, the beauty of logic in the learning process, and form the habit of discovering beauty, then their learning interest and motivation will be greatly enhanced.

\section{B. Promote the Implementation of Aesthetic Education Practice}

Network brings people great convenience, presenting novels, drama, poetry, music, dance, painting and other arts in front of people in the expression form with more impact, 
forming a strong appeal to people, especially the teenagers, most of them cannot help themselves facing the various temptation of network. But when people are watching all kinds of network works, they tend to ignore the real world and aesthetic practice that has brought the unlimited vitality to this beauty. Aesthetics shall return to the colorful life practice, and cannot simply pursue the higher-level sermons and abstract system. Only in this way can the aesthetic boot on the ground to obtain a steady stream of nourishing, to have the strong vitality. [3]

- Realize the benign interaction of network space and aesthetic education practice. With the development of network technology, more and more arts are spread on the Internet, and more and more people can experience the sense of beauty and enjoyment brought by various artistic works. But if we just stay at the stage of online appreciation, it is not conducive to the practical experience of various aesthetics and the interaction of perception. Therefore, while making artistic works entering into network for publicity and promotion, they shall be allowed to walk out of the network, to enable more youth to participate in the reality and experience the beauty of poetry recitation and the harmonious beauty between dance and the body, as well as the integration beauty of music and emotion.

- Give play to positive experience of aesthetic practice. Experience is a kind discovery and investment. In the field of psychology, experience is a "psychological process that a person is moved by nature and art, and even fascinated in it, and fully emerged in it". It is the profound experience with the whole personality to be invested in it. [4] Experience is the process of main body's experience, perception, taste and verification, integrating students' positive integration process, playing an irreplaceable role on students' personality and moral character formation. [5] Therefore, the youth shall be promoted to actively participate in all kinds of the theme activities in reality, to enhance practical aesthetic experience.

\section{Build A Team of Aesthetic Education Network Teachers}

In September 2014, general secretary Xi Jinping said that "the teachers must set an example, to guide and help students to grasp their life direction, especially guide and help them to have a good first step in their life" while he was having an informal discussion with the students of Beijing Normal University. Teachers influence students with their extensive expertise and modest personality, similarly the teachers' aesthetic quality and aesthetic accomplishment will also have a significant impact on students. Therefore, teachers' aesthetic cultivation shall be strengthened, offering them the external and internal cultivation in the real world, and dare to make a statement, to make clear of their own aesthetic standards, to pass through truth, kindness and beauty through network, so as to have good influence on students, and play the role of demonstration and leading for them.

In addition, network has strengthened the interaction between teachers and students. Teachers can make full use of network to show students of all kinds of artistic and literary works, enabling various beauties to be presented in front of students directly in class, and they can also respond to students' feedback in time through network after class, to strengthen the guidance on students, and consciously guide student to recognize, appreciate, experience and create beauty, thus to accept the edification of beauty and enhance aesthetic cultivation.

\section{Build A Good Network Aesthetic Atmosphere by the Whole Society}

Lazarsfeld and Merton, the founders of communication, hold the opinion that "mass media is a power tool that can serve the kindness, but also can serve the evil; on the whole, without proper control, it is more likely to serve the evil".[6] The development of network technology and mass media, provides revolutionary change to the spread of information, but in essence, network should not be just a technical expansion or tool innovation, but also a carrier of humanistic value."[7] Aesthetic education should give full play to the advantages of network, and be developed to be the main position of aesthetic education.

- Network shall not only positively pass the beauty of ancient and modern classic arts, but also shall be of the form beauty of composition, structure and design. In addition, it shall also have the beauty of order, kindness and harmony. As a result, the participants of network activities of the whole society are required to abide by the law of Internet, and create excellent works positively under the premise of not breaking through the moral bottom line, to make the youth free from the harm by bad culture information, enabling them to perceive the beauty of human's outstanding artistic and literary works in the green network space environment, and accept the aesthetic knowledge in network space, so as to enhance their aesthetic accomplishment and enlighten the beauty of soul.

- Hold the network aesthetic theme activities, to form aesthetic culture gravitational field. At present, the network culture is diversified with many vulgar works flowing into it, having bad influence on young students. In this case, the aesthetic themed culture should dare to react and speak, to show the excellent domestic and foreign literary and artistic achievements of both ancient and modern times. The methods that teenagers are willing to accept can be adopted for aesthetic education, for example, the network aesthetic theme exhibition, network aesthetic knowledge game and other methods, to take the initiative to enter into the teenagers' network world, form the mainstream voice of network aesthetic education, lead the network aesthetic culture trend, attract more and more teenagers to pay attention to aesthetic knowledge, so that they can improve their aesthetic quality in network aesthetic experience, thus to promote the perfection and allround development of their personality subtly and constantly. 


\section{REFERENCES}

[1] Jin Xin. Aesthetic Education and College Students' Personality Cultivation [D].Chuangchun: Doctoral Thesis of Northeast Normal University, 2009.

[2] Teng Shouyao. Key to the Modernization of Aesthetic Education [J]. Journal of Peking University (Philosophy and Social Sciences Edition), 1995(2).

[3] http://theory.people.com.cn/n1/2016/0125/c40531-28080749.html

[4] Edited by Yi Tianxin, and translated by Yang Zongyi. Psychology of Adolescence $[\mathrm{M}]$. Beijing: Beijing Knowledge Publishing House, 1981:73

[5] The same as [1].

[6] Pu Qingping, Zhang Weili, Zhao Nan. Micro-culture: Characteristics, Risk and Value Guidance [J]. China Youth Study, 2016 (1)

[7] Wang Zhuofei. Reflection on Network Communication [J]. Journal of Fujian Normal University, 2007(1) 